\title{
Post-Disaster Reconstruction of Alishan Tsou Tribe in Different Place and Sustainable Development
}

\author{
Hsiao-Ming Chang1, Chiu-Hui Hung', Han-Ming Lin ${ }^{3 *}$ \\ ${ }^{1}$ School of Physical Education, Putian University, Putian, China \\ ${ }^{2}$ Department of Tourism, Leisure and Entertainment Management, Tatung Institute of Technology, Taiwan \\ ${ }^{3}$ Department of Tourism Culture, Kun Shan University, Taiwan \\ Email: 1815649662@qq.ocm, chiuhui@ttc.edu.tw, ‘hanming57@gmail.com
}

How to cite this paper: Chang, H.-M., Hung, C.-H. and Lin, H.-M. (2021) PostDisaster Reconstruction of Alishan Tsou Tribe in Different Place and Sustainable Development. Open Journal of Applied Sciences, 11, 458-468.

https://doi.org/10.4236/ojapps.2021.114033

Received: February 28, 2021

Accepted: April 18, 2021

Published: April 21, 2021

Copyright $\odot 2021$ by author(s) and Scientific Research Publishing Inc. This work is licensed under the Creative Commons Attribution International License (CC BY 4.0).

http://creativecommons.org/licenses/by/4.0/

\begin{abstract}
After the Morakot disaster in 2009, the affected indigenous tribes suffered from the government's use of permanent housing as a single reconstruction option, which forced the victims to leave their original land for a new life in a different reconstruction mode. The purpose of this study is to explore the ways adopted by tribal residents to maintain their own culture and tribal life in the process of disaster, post disaster reconstruction and post disaster adjustment. Veoveoana Village in Taiwan is an indigenous tribe that relocated after a disaster and was reconstructed and developed through tourism development. This study performed the research by participant observation and in-depth interviews on Veoveoana Village. The analytical results showed that: 1) development of the tourism industry can result in cultural reconstruction of the post-disaster tribe and maintain the people's incomes; 2) although the government constantly assists with the rehabilitation of tribal industry by various policies, the implementation cannot effectively continue and the outcome is insignificant; 3) due to the gap between permanent prefabricated housing and original tribal cultural features, the residential rate is not high. According to the research findings, it is suggested that, in the process of post-disaster reconstruction, the government and private non-profit organizations should respect the intention of the majority of the indigenous people. In addition, it should cultivate professional manpower for the subsidized projects.
\end{abstract}

\section{Keywords}

Post-Disaster Reconstruction, Typhoon Morakot, Indigenous Tourism, Veoveoana Village, Tsou Culture 


\section{Introduction}

\subsection{Research Background and Motivation}

In recent years, climatic change has become an important international issue, as natural disasters severely destroy and affect human life. Moreover, it results in the following social problems, which must be encountered and concerned by all countries [1]. Significantly destructive natural disasters not only cause great amounts of property and non-property loss for the countries or communities, they also change the residents' original life style and environment. It can also result in the residents' mental and cognitive trauma [2]. Some places become uninhabitable after disasters, and people should move for the reconstruction. After rehabilitation, residents in the communities should adapt to the change. The goal of the communities rehabilitated in different places is to recover their original life; however, they encounter various challenges, such as the construction of buildings, public facilities, environment, culture, streets, and the arrangement of the residents' housing. After the establishment of community structure, how the residents make a living is one of the issues encountered [3]. On August 8, 2009, Typhoon Morakot struck southern Taiwan and caused serious flooding, landslides, damage of houses, land subsidence, and cracks of houses, which resulted in significant damage in the indigenous areas of central and southern Taiwan. It was Taiwan's largest flood in the past 50 years, thus, some victims of Tsou tribesmen in eight tribes of Alishan (Dabang, Tefuye, Shanmei, Lijia, Chashan, Xinmei, Leye, and Laiji) moved to Veoveoana Village. Due to the location of Veoveoana Village and policy, the development of the tourism industry became the main focus of industrial rehabilitation after the disaster. Thus, the purpose of this study is to determine how Tsou tribesmen make a living through the tourism industry after their reconstruction in a different village. How do they develop identity through tourism development? In modern times with disasters caused by extreme climatic change, the findings of this study aim to serve as a reference for indigenous tribes and communities of post-disaster reconstruction in other countries.

\subsection{Research Method}

This study mainly uses three research methods, the first is literature analysis, the second is observation, and the third is interview. They are described below.

\subsubsection{Documentary Analysis Method}

First, through the data of the Morakot Reconstruction Committee, the research papers on the indigenous tribes of Alishan, and the official website of Alishan National Scenic Spot, to learn about the process of the reconstruction of Veoveoana tribes. Second, to find out the situation of Veoveoana and the development of local tribal tourism through web search.

\subsubsection{Observation Method}

In the second stage of this study, we went to the Veoveoana tribe and visited all 
the streets in the tribe to understand the actual development status, whether the tourism of the local tribe is in line with the objectives of the Morakot Reconstruction Committee and the tribal tourism development policy planning.

\subsubsection{Interview Method}

In the third stage of this study, we interviewed the indigenous people (tribal residents, dance performer, souvenir shop, restaurant operators, Tribal Development Association) of the local tribes. In addition, the researchers also interviewed tourists to understand their views on the development of tourism in the tribe. The outline of the interview is as follows:

1) How do you adapt to this new environment when you leave the tribe that used to live in Alishan?

2) How do the residents of the tribe get along with each other when they leave their original living environment and go to this new living tribe?

3) At present, the main purpose of the tribe is to develop tourism industry. Do you think it will be helpful to everyone's income and the development of the tribe?

4) How do you feel when you come to the Veoveoana tribe? Do you experience the cultural characteristics of Tsou nationality? (This is an interview with tourists)

In this study, after the interview, we first make the interview data into a verbatim manuscript, and then analyze the results of literature analysis and actual observation. In order not to produce the subjective judgment of researchers, the result discussion adopts the way of joint analysis, in order to obtain a consistent consensus, and then write the results of the analysis.

\section{Introduce of Tsou Ethnic Group and Typhoon Morakot Impact}

\subsection{Tsou Ethnic Group and Alishan}

Alishan is the hometown of the Tsou ethnic group of Taiwan's indigenous peoples. Alishan Township is located in the eastern part of Chiayi County, Taiwan, with an altitude from 360 meters to 3952 meters. The Tsou tribesmen have experienced several emigrations. The earliest Tsou tribesmen have arrived in this beautiful island of Taiwan about 3000 to 4000 years ago. Before the legendary great flood, the Tsou tribesmen had been active in the area of the Jianan Plain. After thousands of years of tossing and migrating, they finally settled in the current Alishan Mountains and the upper reaches of Zengwenxi and Zhuoshuixi. Due to the introduction of Western religions in modern times, the Tsou tribesmen believed in Catholicism, Presbyterianism, and True Jesus religion. However, the traditional religious ceremonies of the Tsou tribesmen still exist and continue. All traditional ceremonies of the Tsou tribesmen are held in Taisha (Dabang, Tefuye), similar to the so-called "ancestral hall" of the Han people. The millet harvest festival (Homeyaya) of the Tsou tribesmen is held in each clan home between July and August. The Zou tribesmen think that the Xiaomi god is 
a female, so in the early agricultural production roles were mainly played by females in the family, and Homeyaya was an important ceremony for females. In the traditional Homeyaya ceremony, the elders of the Tsou tribesmen decided whether the war festival (Mayasvi) was held and the exact time according to whether they had captured human heads, renovated the clubhouse, or whether many unfortunate disasters or diseases occurred. The current Mmayasvi ritual process has been greatly simplified. Only the simple "Road Festival", the symbolic "Enemy Festival" and "Adult Ceremony" have been retained. KUBA (Men's Assembly Hall) is held in turn. Mayasvi, this grand ceremony is mainly "to commemorate the past wars, but also to pray for all the inevitable victory in the future." Its objects are the highest god of the gods (Hamo), the god of war (Iafafejoi) and the god of life (Bosonfihi), and even the spirit (Hitsu) of the hunter. So this ceremony also has the meaning of inviting souls to repose [4]. After the foundation of Alishan National Scenic Area, the government not only began to actively promote Tsou culture tourism but also the features of different tribes. The Leye tribe is featured by mountain tea, coffee, and diverse ecological trails and ancient roads, while Dabang and Tefuye feature men's communal buildings, known as kuba, which are unique buildings in these tribes. In the Laiji tribe, there are several ancient trails with abundant ecological systems. However, the external access is inconvenient and is located far from Alishan Highway. As to the three villages in the south, the Xinmei tribe is based on organic agriculture and the Shanmei tribe is well-known due to the Danayiku Ecology Park. The Chashan tribe is the southernmost village of Alishan Township, and its main features are wooden twitch grass pavilions and rich eco-resources in the surroundings. The Laiji tribe is located at the bottom of Ta Mountain, the holy mountain of Tsou, and its motto is wild boar and handicrafts based on Tsou culture [5].

\subsection{Typhoon Morakot Impact}

Typhoon Morakot brought record breaking rainfall to the central and southern mountainous areas of Taiwan. The 72 hour accumulated rainfall in Alishan area reached $3059.5 \mathrm{~mm}$, which was the highest rainfall in Taiwan over the years. The 24-hour and 48 hour accumulated rainfall was $1623.5 \mathrm{~mm}$ and $2361 \mathrm{~mm}$, which was close to $1825 \mathrm{~mm}$ and $2467 \mathrm{~mm}$ of the extreme rainfall in the world [6]. Moreover, the maximum rainfall of $3059.5 \mathrm{~mm}$ fell here. Twenty-five bridges in the township of Alishan were washed away and 23 bridges were destroyed, which shows that the damage is powerful. Continuous heavy rain, torrential floods, earth rock avalanche and flooding, resulting in traffic disruption and isolated islands and other complex disasters. The disaster area is large, resulting in major flooding disaster [6]. After Typhoon Morakot, the reconstruction areas of Tsou ethnic group in Alishan include Shanmei permanent house, Laiji permanent house, Leye permanent house, and Veoveoana permanent house in Fanlu township. Among the permanent houses mentioned above, Tsou tribe has the widest permanent house base, which is also the area where eight Tsou tribes live with a few 
Han people. In addition to building 156 permanent houses in the Veoveoana tribe, there are also public spaces reserved for the construction of the deer chasing Museum, the activity center and three churches. The churches are set up by the various denominations with their own funds. There are Catholic Church (see Figure 1), Presbyterian Church (see Figure 2) and Jesuit Church, which provide people with spiritual and religious sustenance in the permanent house.

Because Typhoon Morakot continued to the indigenous people, and caused great damage to the cultural heritage. Although the government hopes to resettle the victims as soon as possible, so that they can have a shelter and recover quickly. However, the Taiwan government and some non-profit organizations did not take into account the cultural differences of the indigenous peoples and quickly decided on the permanent housing policy, which did not give them any space to participate in the discussion and consultation. As a result, the indigenous people have to adapt to the culture and stay away from the ancestral spirit and the original land, so they have to face the problem of rebirth in other places after the disaster [7].

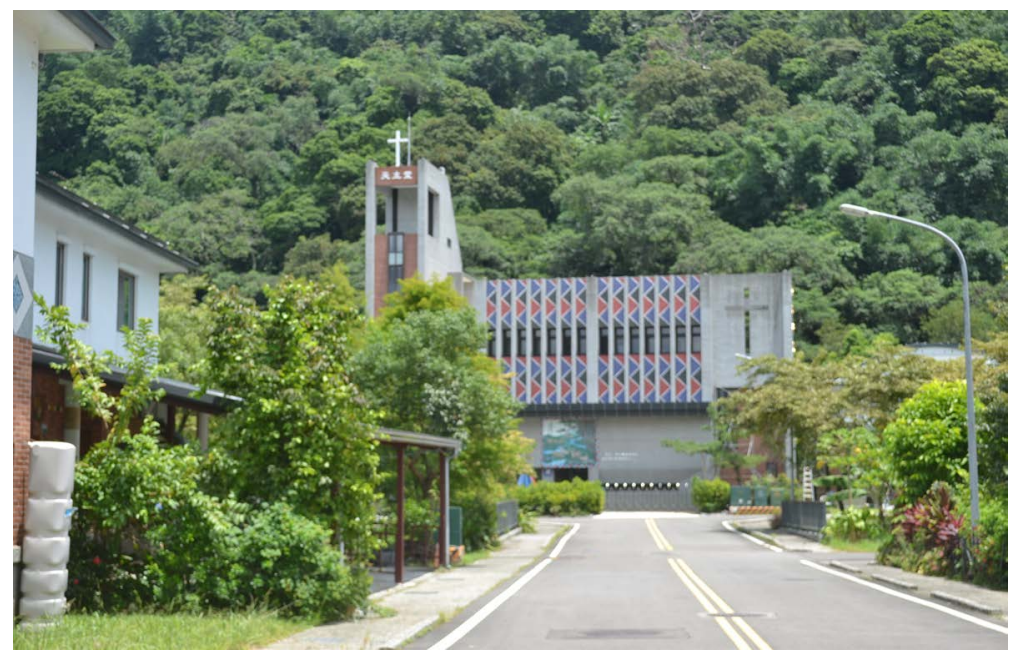

Figure 1. Catholic church.

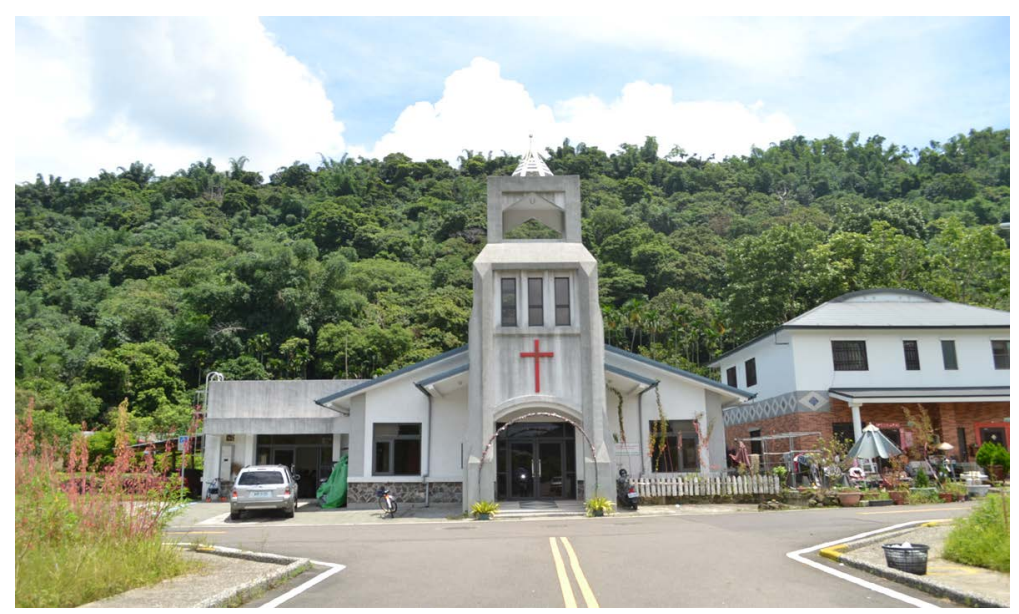

Figure 2. Presbyterian church. 


\section{Reconstruction and Development of Veoveoana Village}

Veoveoana in Tsou language means "the place to hunt sika deer". After Typhoon Morakot, some tribesmen were forced to leave their familiar homeland and move to the Veoveoana Community at the foot of the mountain. The tribesmen in Alishan originally lived mainly with agriculture; however, their tribes were destroyed by the calamity. Although they lived in permanent prefabricated houses, their industrial development changed from the past. In the tribe, the Red Cross Society constructed the permanent prefabricated houses, and the community was "collectively moved to the nearest and appropriate place" in the rehabilitation project after Typhoon Morakot, which was launched in December 2012, and a total of 156 houses were constructed. However, according to the subjects of the tribe, less than half of the indigenous people continued to live in the tribe, as some moved to different places since they encountered the difficulty of adaptation and some returned to the mountain for agricultural work.

Since the tribe was located next to the Alishan Chukou Visitor Center, which was the entrance to Alishan, tourism development became the focus in the process of reconstruction. In March 2013, the Yokeoasu holiday market was launched, and in September 2013, the "Veoveoana Community Development Association" was founded in the tribe. In October, the "Veoveoana Community Cooperative" was established, and the main purpose was to preserve community culture, plan Tsou Tribe art activities, found the sales of markets, and develop tribal tourism. Another important task of the association was to integrate the internal affairs of the tribe, construct mental rehabilitation for tribesmen after the disaster, and manage the elderly health care, emergency aid, and collective community construction of the tribe. The aim of the cooperative referred to the tourist market, which stimulated the tribal economy by making profits and allowed the tribesmen to earn a living (see Figure 3, Figure 4).

According to the tribesmen who currently live in the tribe, in the process of rehabilitation, besides constructing the permanent prefabricated houses as the tribesmen's residence, they established performance stages and held holiday markets, including Tsou singing and dancing performances, traditional art

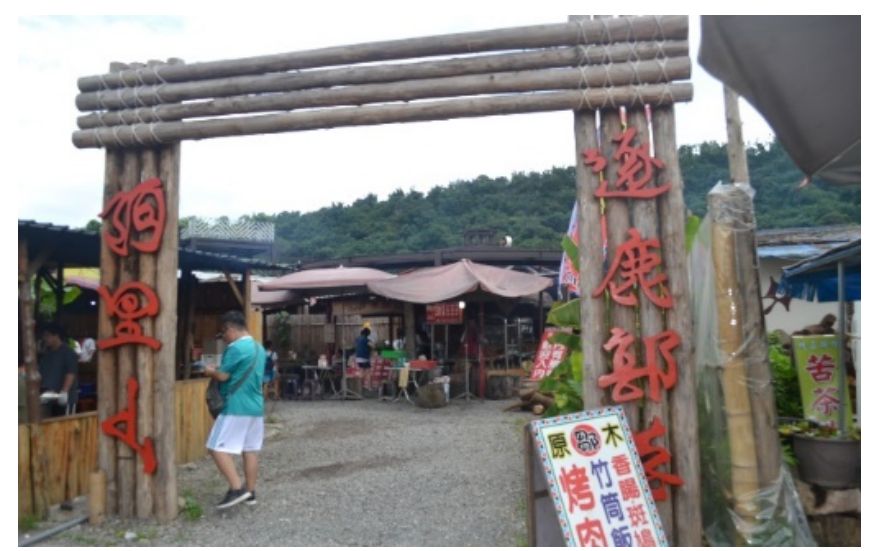

Figure 3. Entrance of the market of Veoveoana Village. 


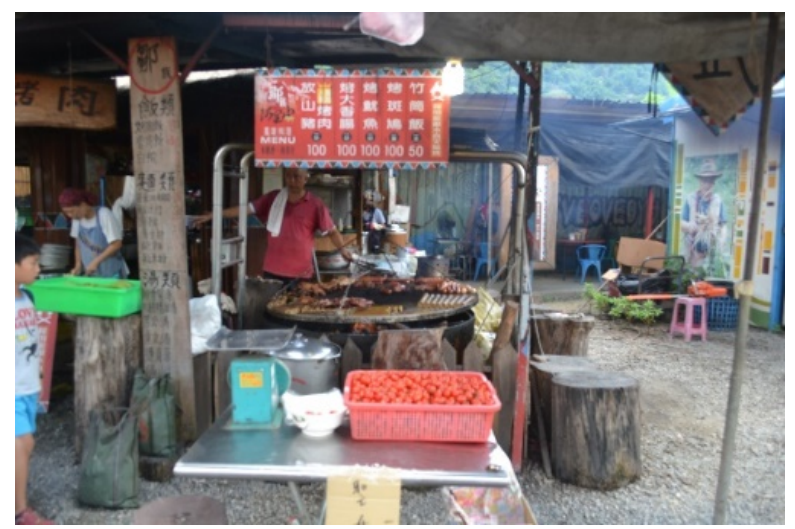

Figure 4. Stone BBQ of Veoveoana Village.

works, cultural fine foods, and agricultural specialties. Thus, the visitors not only experience and appreciate the beauty of the traditional culture of indigenous people, but also recognize their morale and vitality. Hence, the tribesmen can continue their traditional culture (see Figure 5, Figure 6).

On the stages next to Veoveoana Market, on weekends and holidays or with group reservation, there are regular singing and dancing performances every morning and evening. The tourists can watch Tsou traditional dance performances, which show the cultural characteristics of the Tsou Tribe, as well as important rituals, such as the battle cultural festival, millet festival, etc.

According to this study, after the typhoon, some tribesmen lost their land and houses on the mountain, thus, they moved to Veoveoana Village (see Figure 7). Ancestors of the tribesmen have lived in the mountains for generations, and lived self-sufficient lives. However, when they moved to the new environment and the permanent prefabricated houses, it did not resemble the indigenous homes the tribesmen had expected, thus, some tribesmen decided to leave Veoveoana Village (see Figure 8).

According to the interviews with tribesmen, the directors of the development association, and community cooperatives, after the typhoon, the previous problems did exist. However, at present, the tribes of Alishan have successively developed their tribal features, such as agricultural transformation and tourism development. Regarding agriculture, most of the Tsou tribesmen continue the cultivation of seasonal farm products, such as bamboo shoots, vegetables and fruits, jelly fig seeds, and tea. In addition, some tribesmen have begun the cultivation of high cash crops, including coffee, Alishan Thistle, cocoa trees, Sacha Inchi, etc. Regarding the development of the tourism and leisure industry, in recent years, the Alishan National Scenic Area Administration assists with postdisaster reconstruction in the tourism spots of different tribes, as well as the development of trips and festivals with tribal characteristics, such as the Chashan Hufu Festival, Xinmei Hunters Cultural Festival, Shanmei Saviki Xenopus Festival, Leye Coffee Cultural Festival, Laiji Thanksgiving Festival, Lijia Firefly Festival, Dabang Mayasvi Festival, Tefuye Homeyaya Festival, and Veoveoana Sharing Festival. 


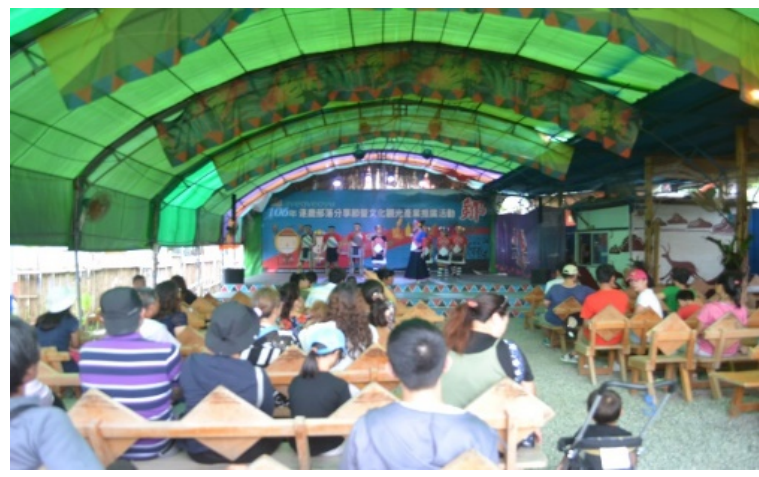

Figure 5. Tsou traditional dance performance in Veoveoana Village.

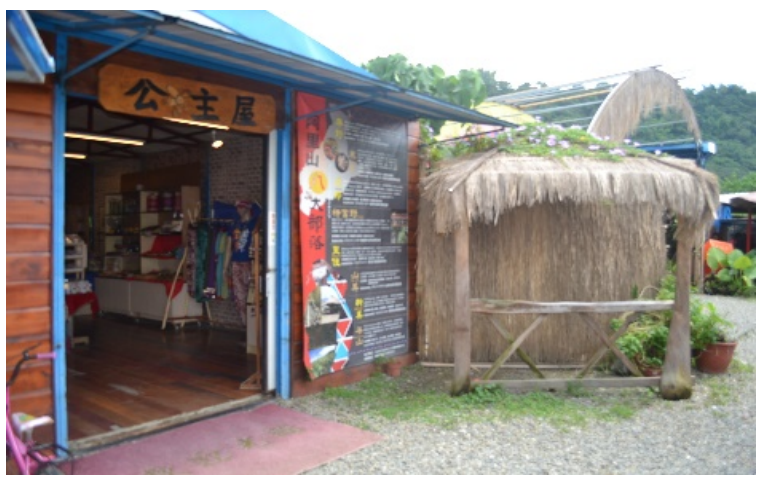

Figure 6. Tsou handicraft store in the market.

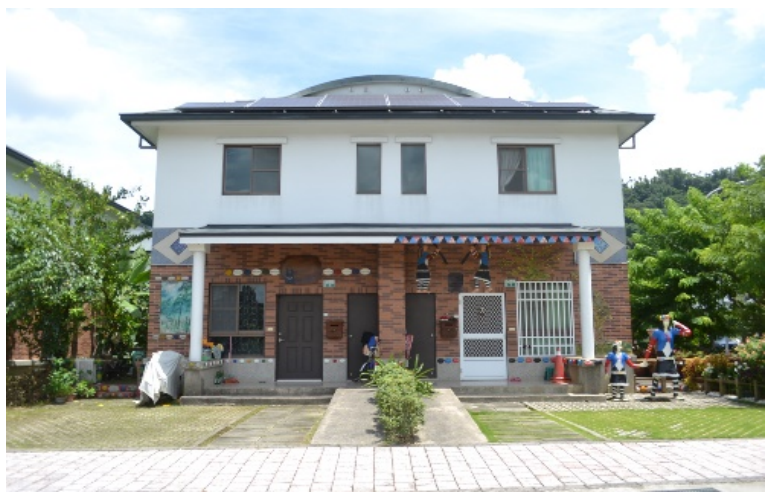

Figure 7. Permanent prefabricated housing of Veoveoana Village (1).

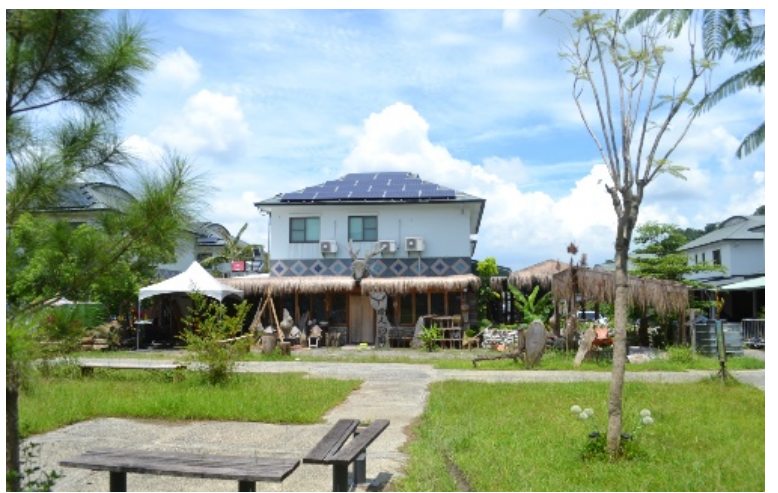

Figure 8. Permanent prefabricated housing of Veoveoana Village (2). 


\section{Discussion}

Regarding the reconstruction of the tribal development of tourism, this study shows that, with indigenous traditional dance, fine food, wood carving, weaving, and leather carving, Tsou tribesmen who lost their homeland have returned to their original tribal life [8]. In addition, as the reconstruction location of the tribe is next to Alishan National Scenic Area Administration, and it is the main road to enter Alishan, tourists stay, visit the tribal market, and appreciate the cultural features of the permanent prefabricated houses and Tsou Tribe. Moreover, Alishan is one of the important spots for Chinese tourists, and visiting the tribe and watching Tsou Tribe dance performances become part of their trip. The aforementioned meets four related factors (4H), as proposed by Smith (1996), to analyze tourism development of indigenous peoples: geographical environment (habitat), tradition of anthropology (inheritance), cultural impact (history), and art works for sale [8]. When tourists visit indigenous areas or tribes, they are interested the most in the unique and spiritual connection between the culture and the land, meaning their values, beliefs, skills, and knowledge related to culture and history, as well as the change of indigenous peoples' development. Besides performances and guides, the most important financial income for indigenous peoples is their art works, which are the indigenous products most purchased by tourists. However, according to the interviewed tribesmen, in recent years, due to Cross-Strait relations, the number of Chinese tourists is reduced, which affects their incomes.

The design of tribal hardware reconstruction is based on indigenous peoples' culture, which significantly enhances social cohesion and persistence, and lowers the risk of calamity. Nevertheless, permanent prefabricated housing is different from traditional Tsou buildings. Although the houses are interesting and show indigenous culture to the tourists, it is unrealistic. The main reason is that tribal space planning after a disaster relies on the government and non-profit organizations, and tribesmen encounter obstacles to develop their ideas for tribal construction, which results in the reduction of its population. This issue is one of the factors affecting the development of the tribal tourism industry. According to interviews with tourists, the permanent prefabricated houses are attractive, clean, and decorated with the cultural totems of the Tsou Tribe, and the village resembles a European community. However, it is not realistic. Indigenous peoples have traditional houses. The design of their rehabilitated houses should be based on the cultural characteristics of the Tsou Tribe.

Another critical factor is the land. Indigenous peoples are the same as those in other coun tries; for example, Notzke (2004) argued that, for indigenous peoples in Canada, the land is the source of their food, political identity, and culture. Indigenous peoples in Australia are no exception. They create a positive and sacred climate of the land [9]. Unfortunately, the indigenous peoples of post-disaster reconstruction are always the subjects "to be reconstructed". They cannot actively rehabilitate the tribe; while the permanent prefabricated houses are built 
with love, in fact, they imply the violence caused by inequality of rights, the performance and administrative efficiency required by the officers, and regular "disaster-fund raising-report-fund raising" procedure in the Han charity organizations. In the process, they are not concerned about indigenous peoples' affection for their motherland. For indigenous peoples in Taiwan, the land it not only the cultural inheritance, but also the symbol of sovereignty. Hence, many Tsou tribesmen who lost their home after Typhoon Morakot were not willing to live in "modern European buildings" which do not belong to their land or traditional tribe.

Although the government assisted with sustainable tribal development with plenty of funds and projects, the execution could not be continued. According to the interviews with the members of the development association, "indigenous peoples are normally optimistic and casual. They tend to work hard at the beginning of a project and subsidy, spend all they earn, and then, look for other jobs. With plenty of governmental resources, they became inactive. Most of them returned to the mountains to work on their fields". In addition, according to the management of the development association, the government is willing to assist with the tribal development as long as the tribes brainstorm with the development of industry, as governmental resources rely on independent development ideas from the tribes. For example, developments in Chashan Village, Laiji Village, and Shanmei Village are mature, young people are willing to return to and work on their homeland, and the government shows the intention to enhance their industrial development.

\section{Conclusions and Suggestion}

\subsection{Conclusion}

Based on the research findings, after a typhoon, the key is the government's assistance with tribal rehabilitation by integrating nonprofit and public welfare organizations. With the efforts of the tribal development association and cooperatives, tribesmen can maintain their financial sources. Through tourism development, they can exchange, assist each other, and show community cohesion, which strengthens post-disaster community sustainable development. However, there is gap between the modern hardware construction of post-disaster reconstruction and traditional Tsou buildings, which causes a contradiction in the process when the tribe promotes indigenous culture and tourism. Moreover, various post-disaster reconstruction projects implemented by the government become ineffective, as the execution is not continued.

\subsection{Suggestion}

According to this study, the purpose of the tourism tribal visits is to experience indigenous culture; however, modern hardware construction of post-disaster reconstruction does not meet their expectation, as they intend to visit the traditional cultural totems and buildings of the Tsou Tribe. Thus, the tribe should attempt to restore its traditional tribal buildings; for example, they can construct 
traditional houses that represent the Tsou Tribe, where tourists can experience Tsou Tribe culture with explanations. Although the government subsidizes tribal development with positive intention, there are limits. In the execution of projects, the government should instruct tribal community association members to legally and efficiently use the funds. In addition, the monitoring system and objectives are essential. Most importantly, in future projects to reconstruct tribes after a natural disaster, indigenous peoples' opinions should be included, instead of only relying on the thoughts of the authorities.

\section{Fund}

This study was supported by a grant from National Social Science Foundation of China (No. 18BMZ130).

\section{Conflicts of Interest}

The authors declare no conflicts of interest regarding the publication of this paper.

\section{References}

[1] Xu, J., Wang, Z., Shen, F., Ouyang, C. and Tu, Y. (2016) Natural Disasters and Social Conflict: A Systematic Literature Review. International Journal of Disaster Risk Reduction, 17, 38-48. https://doi.org/10.1016/j.ijdrr.2016.04.001

[2] Benight, C.C., Ironson, G., Klebe, K., Carver, C.S., Wynings, C., Burnett, K. and Schneiderman, N. (1999) Conservation of Resources and Coping Self-Efficacy Predicting Distress Following a Natural Disaster: A Causal Model Analysis Where the Environment Meets the Mind. Anxiety, Stress \& Coping: An International Journal, 12, 107-126. https://doi.org/10.1080/10615809908248325

[3] Tarlow, P. and Korstanje, M.E. (2013) Disasters, Tourism and Mobility, the Case of Japan Earthquake. Pasos. Revista de Turismoy Patrimonio Cultura, 11, 7-32. https://doi.org/10.25145/j.pasos.2013.11.035

[4] Alishan National Scenic Area Administration (2020) Tsou Tribal Village Short Trip to Visit Tribal Village and Experience Indigenous Culture. https://www.ali-nsa.net/zh-tw/attractions/recreation-area\#tsou-culture-area

[5] Chern, J.-C. (2019) Reconstruction after Typhoon Morakot: Achievements and Reflection on Its 10th Anniversary (I) - Prologue \& Infrastructure Built for Disaster Prevention and Sustainability. Civil Engineering and Water Conservancy, 46, 5-13.

[6] Lin, W.-C. (2019) Social Resilience Perspective of "Build Back Better" on Culture and Tourism Development of the Poftonga Veoveo Tribe after Typhoon Morakot. Unpublished Master Thesis, Central Police University, Taiwan.

[7] Chang, H.-M., Hung, C.-H. and Huang, Y.-C. (2019) The Influence of Tourism on Indigenous Support Attitude in Alishan Tribe: Using Quality of life as a Mediating Variable. Open Journal of Applied Sciences, 9, 857-869.

https://doi.org/10.4236/ojapps.2019.912069

[8] Smith, V. (1996) Indigenous Tourism: The Four Hs. In: Butler, R.W. and Hinch, T.D., Eds., Tourism and Indigenous Peoples, International Thomson Business Press, Toronto, 283-307.

[9] Notzke, C. (2004) Indigenous Tourism Development in Southern Alberta, Canada: Tentative Engagement. Journal of Sustainable Tourism, 12, 29-54.

https://doi.org/10.1080/09669580408667223 